\title{
China's Mars Exploration Mission and Science Investigation
}

\author{
Chunlai $\mathrm{Li}^{1,2}$ - Rongqiao Zhang ${ }^{3}$ - Dengyun $\mathrm{Yu}^{4}$. Guangliang Dong ${ }^{5}$ Jianjun Liu ${ }^{1,2}$. \\ Yan Geng ${ }^{3}$. Zezhou Sun ${ }^{6}$. Wei Yan ${ }^{1} \cdot$ Xin Ren $^{1}$ - Yan Su ${ }^{1,2}$. Wei Zuo ${ }^{1,2}$. \\ Tielong Zhang ${ }^{7,8}$. Jinbin Cao ${ }^{9}$. Guangyou Fang ${ }^{10}$. Jianfeng Yang ${ }^{11} \cdot$ Rong Shu $^{12}$. \\ Yangting Lin $^{13}$. Yongliao Zou ${ }^{14}$. Dawei Liu ${ }^{1}$ • Bin Liu ${ }^{1}$ • Deqing Kong ${ }^{1}$ - Xinying Zhu ${ }^{1}$. \\ Ziyuan Ouyang ${ }^{1,15}$
}

Received: 31 August 2020 / Accepted: 11 May 2021 / Published online: 25 May 2021

(C) The Author(s) 2021

\begin{abstract}
China's first Mars exploration mission (HuoXing-1) has been named as 'Tianwen-1' meaning Heaven Inquiry. Tianwen-1 was launched on July 23, 2020. In this paper, the scientific objectives of earlier and current Mars exploration missions worldwide are reviewed, and the scientific objectives, payloads and preliminary scientific investigation plan of China's first Mars exploration mission are introduced, and expected scientific achievements are analyzed.
\end{abstract}

Keywords Mars exploration · Payloads · Remote sensing exploration · In-situ exploration · Scientific investigation plan

\section{Introduction}

As the neighbor of the Earth, the Mars evolution is of significant importance for understanding the history and future evolution of the Earth. Since 1960s, more than 40 Mars exploration missions have been implemented, and some more are in progress. According to the collected data, there may have been life and liquid water on Mars, which makes the Mars a potential habitable planet in the solar system, providing new hope for human's migration to Mars and opening up new living space. Exploring information regarding life on Mars, whether life ever existed in the past, and the environment suited for living becomes hot topic of Mars exploration at present (Ouyang and Xiao 2011; Ouyang and Liu 2009). Scientific objectives in the past 20 years (Table 1) provide reference for China's Mars exploration. The scientific objectives and results of recent Mars missions are focused on the following aspects:

(1) Mars atmosphere characteristics and climate change: to examine the structure and composition of Mars neutral atmosphere, meteorology, climate characteristics and changes; to search for evidence on past climate change, and to study the evolution history and future trends of Mars meteorology and climate (Gómez-Elvira et al. 2012; Mahaffy et al. 2013; Barlow 2014; Jakosky et al. 2015).

The Huoxing-1 (HX-1) / Tianwen-1 (TW-1) mission to Mars

Edited by Chunlai Li and Jianjun Liu

Extended author information available on the last page of the article 
Table 1 Mars exploration missions and scientific objectives in the past 20 years

\begin{tabular}{|c|c|c|}
\hline Mission & $\begin{array}{l}\text { Launch/end } \\
\text { of mission }\end{array}$ & Scientific objectives \\
\hline $\begin{array}{l}\text { Mars Odyssey } \\
\text { (Saunders et al. 2004) }\end{array}$ & $\begin{array}{l}2001-4-7 \\
\text { in progress }\end{array}$ & $\begin{array}{l}\text { (1) Globally map the elemental composition of the surface } \\
\text { (2) Determine the abundance of hydrogen in the shallow sub- } \\
\text { surface } \\
\text { (3) Acquire high spatial and spectral resolution images of the } \\
\text { surface mineralogy } \\
\text { (4) Provide information on the morphology of the Martian sur- } \\
\text { face } \\
\text { (5) Characterize the Martian near-space radiation environ- } \\
\text { ment as related to radiation-induced risk to human explor- } \\
\text { ers }\end{array}$ \\
\hline
\end{tabular}

Mars Express

(Wilson and Chicarro 2004)

Spirit Mars Rover

(Crisp et al. 2003)

Opportunity Mars Rover (Crisp et al. 2003)
2003-6-2

in progress

(1) Global color and stereo high-resolution imaging with about $10 \mathrm{~m}$ resolution and imaging of selected areas at $2 \mathrm{~m} / \mathrm{pix}$

(2) Global IR mineralogical mapping of the surface

(3) Global radar sounding of the subsurface structure down to $1-2 \mathrm{~km}$ depth

(4) Long term monitoring of atmospheric parameters: temperature, composition, dust loading

(5) Long-term monitoring of plasma environment and ion escape rate

(6) Global imaging and investigation of Phobos

(7) Infer critical information on the atmosphere, ionosphere, surface and interior

(1) To investigate landing sites which have a high probability of containing evidence of the action of liquid water

(2) To search for and characterize a diversity of rocks and soils that hold clues to past water activity

(3) To extract clues related to the environmental conditions when liquid water was present and assess whether those environments were conducive for life

(4) To determine the spatial distribution and composition of minerals, rocks and soils surrounding the landing sites

(5) To determine the nature of local surface geologic processes from surface morphology and chemistry

(6) To calibrate and validate orbital remote-sensing data and assess the amount and scale of heterogeneity at each landing site

(7) To identify and quantify relative amounts of specific mineral types that contain $\mathrm{H}_{2} \mathrm{O}$ or $\mathrm{OH}$, or are indicators of formation by an aqueous process

(8) To characterize the mineral assemblages and textures of different types of rocks and soils and put them in geologic context 
Table 1 (Continued)

Mission $\quad \begin{aligned} & \text { Launch/end Scientific objectives } \\ & \text { of mission }\end{aligned}$

\section{Mars Reconnaissance}

Orbiter

(Graf et al. 2005)

Phoenix Mars Lander

(Smith et al. 2008)

2005-08-12

in progress

(1) Characterize Mars's seasonal cycles and diurnal variations of water, dust, and carbon dioxide

(2) Characterize Mars's global atmospheric structure, transport and surface changes

(3) Search sites for evidence of aqueous and/or hydrothermal activity

(4) Observe and characterize the detailed stratigraphy, geologic structure, and composition of Mars surface features

(5) Probe the near-surface Martian crust to detect subsurface structure, including layering and potential reservoirs of water and/or water ice

(6) Characterize the Martian gravity field in greater detail relative to previous Mars missions to improve knowledge of the Martian crust, lithosphere, and potentially atmospheric mass variation

(7) Identify and characterize numerous globally distributed landing sites with a high potential for scientific discovery by future missions

2007-8-4 2008-11-2
(1) To study the history of the ice and its emplacement mechanisms

(2) To address the affect that subsurface ice has on the local geomorphology of the surface and any layering beneath the surface

(3) To understand local climate and weather

(4) The question of the habitability of the icy soil
Mars Science Laboratory (NASA 2011; Webster et al. 2015)
2011-11-26

in progress
(1) Determine the nature and inventory of organic carbon compounds

(2) Investigate the chemical building blocks of life (carbon, hydrogen, nitrogen, oxygen, phosphorus, and sulfur)

(3) Identify features that may represent the effects of biological processes (biosignatures)

(4) Investigate the chemical, isotopic, and mineralogical composition of the Martian surface and near-surface geological materials

(5) Interpret the processes that have formed and modified rocks and soils

(6) Assess long-timescale (i.e., 4-billion-year) Martian atmospheric evolution processes

(7) Determine present state, distribution, and cycling of water and carbon dioxide

(8) Characterize the broad spectrum of surface radiation, including cosmic radiation, solar particle events and secondary neutrons 
Table 1 (Continued)

Mission $\begin{aligned} & \text { Launch/end Scientific objectives } \\ & \text { of mission }\end{aligned}$

Mars Atmosphere and Volatile Evolution (Jakosky et al. 2015)

\section{Mars Orbiter Mission \\ (MOM)}

(Kumar and Chauhan 2014)

ExoMars 2016 Trace Gas

Orbiter

(ESA 2014)

InSight Mars lander

(NASA 2018; Banerdt et al. 2020)

\section{Hope}

(Sharaf et al. 2020)
2013-11-18 in progress

(1) Measure the composition and structure of the upper atmosphere and ionosphere today, and determine the processes responsible for controlling them

(2) Measure the rate of loss of gas from the top of the atmosphere to space, and determine the processes responsible for controlling them

(3) Determine properties and characteristics that will allow us to extrapolate backwards in time to determine the integrated loss to space over the four-billion-year history recorded in the geological record

2013-11-5 (1) Exploration of Mars surface features, morphology,

in progress (2) mineralogy and Martian atmosphere by five scientific instruments

2016-3-14 in progress

(1) Investigation of the water/geochemical environment as a function of depth in the shallow sub-surface

(2) Study of martian atmospheric trace gases and their sources

(3) Surface stereo and color imaging at $\sim 6 \mathrm{~m} / \mathrm{px}$ resolution

2018-5-5 in progress

(1) Formation \& Evolution: Understand the formation and evolution of terrestrial planets through investigation of the interior structure and processes of Mars

(2) Tectonic Activity: Determine the present level of tectonic activity and meteorite impact rate on Mars

2020-7-20

in progress

(1) characterize the weather system in the lower atmosphere of Mars, providing a comprehensive understanding of diurnal changes across the planet and across all seasons

(2) measure the distribution of hydrogen and oxygen in the highest portions of the atmosphere (the collisionless exosphere)

(3) correlate the processes within the lower atmosphere with rates of atmospheric escape from the exosphere

2020-7-30 in progress

(1) Identify past environments capable of supporting microbial life

(2) Seek signs of possible past microbial life in those habitable environments, particularly in special rocks known to preserve signs of life over time

(3) Collect core rock and "soil" samples and store them on the Martian surface

(4) Test oxygen production from the Martian atmosphere 
(2) Ionosphere, aeronomy, plasma environment and escape processes: to measure the composition and structure of the upper atmosphere and ionosphere, and the rate of loss of gas from the top of the atmosphere to space (Jakosky et al. 2015; Pätzold et al. 2016).

(3) Landform and geological structure: to investigate the Mars topography and geomorphology, geological structure, soil and rock composition and element, sediment rock distribution and relative age, polar water ice distribution and variation; to study the geological history and surface evolution (Carr 1981; Head et al. 1999; Smith et al. 1999; Gendrin et al. 2005; Bibring et al. 2005, 2006; Barlow 2014; Head and Pieters 2018).

(4) Magnetic fields, gravity fields and interiors: to explore Mars crustal and time-varying magnetic fields, Mars' core and magnetism, its gravity field; to comparatively study the interior structure of Mars and the Earth, and to explore the evolution of the earth-like planet (Stevenson 2001; Barlow 2014; Johnson et al. 2020).

(5) Water and life: to search for water on Mars; to study the water body evolution; to seek signs of habitable conditions on Mars in the ancient past, and to search for evidence of ancient life (Grotzinger 2014; Freissinet et al. 2015; Webster et al. 2015, 2018; Orosei et al. 2018; Salese et al. 2019).

(6) Mars science observation station and laboratory: to set up scientific observation station on Mars; to monitor and study the change of Martian surface and climate environment; to explore the possible resources on Mars and to provides scientific basis for the exploration and utilization of resources (Zeitlin et al. 2013; Hassler et al. 2014).

China announced its planetary exploration programme beyond the Earth-Moon system in 2016. Benefiting from the engineering heritage of China's lunar exploration programme, the Chinese national strategy sets Mars as the next target for planetary exploration. China's first Mars exploration mission (HuoXing-1) aims at completing orbiting, landing and roving in one mission, and has been named as Tianwen-1 (TW-1) which means Heaven Inquiry (Wan et al. 2020). TW-1 was launched on July 23, 2020. Here the scientific objectives of earlier and current Mars exploration missions worldwide are reviewed, and the scientific objectives, payloads and preliminary scientific exploration plan of China's first Mars exploration mission are introduced, and expected scientific outcomes are analyzed.

\section{China's First Mars Exploration Mission}

China's first Mars mission can be divided into launch phase, Earth-Mars transfer phase, Mars capture orbit phase, Mars parking orbit phase, EDL (Entry, Descent, Landing) phase and scientific exploration phase. The probe is launched into the Earth-Mars transfer trajectory and will travel for 6 and a half months in this transfer trajectory. After captured by Mars, the probe will enter an ellipsoid Mars orbit of 10 sols. After orbit maneuver at the apoareon, the probe will be adjusted to the circumpolar orbit and then enter the mars parking orbit with a period of about 2 days after three times of periareon braking. Two to three months later, the rover will be released by the orbiter and land on the surface to start in-situ exploration. After releasing of the rover, the orbiter will perform orbit maneuver, enter relay and survey orbit with a period of about 8.2 hours, communicate with the rover and start its scientific exploration. 90 sols later, global reconnaissance orbit phase will start after orbit adjustment and last for one martian year (Fig. 1).

Global reconnaissance orbit is a large ellipse with the altitudes of periareon and apoareon about $265 \mathrm{~km}$ and $11900 \mathrm{~km}$, respectively. The orbit inclination is $90^{\circ} \pm 5$, and the orbital period is 7.8 hours. 


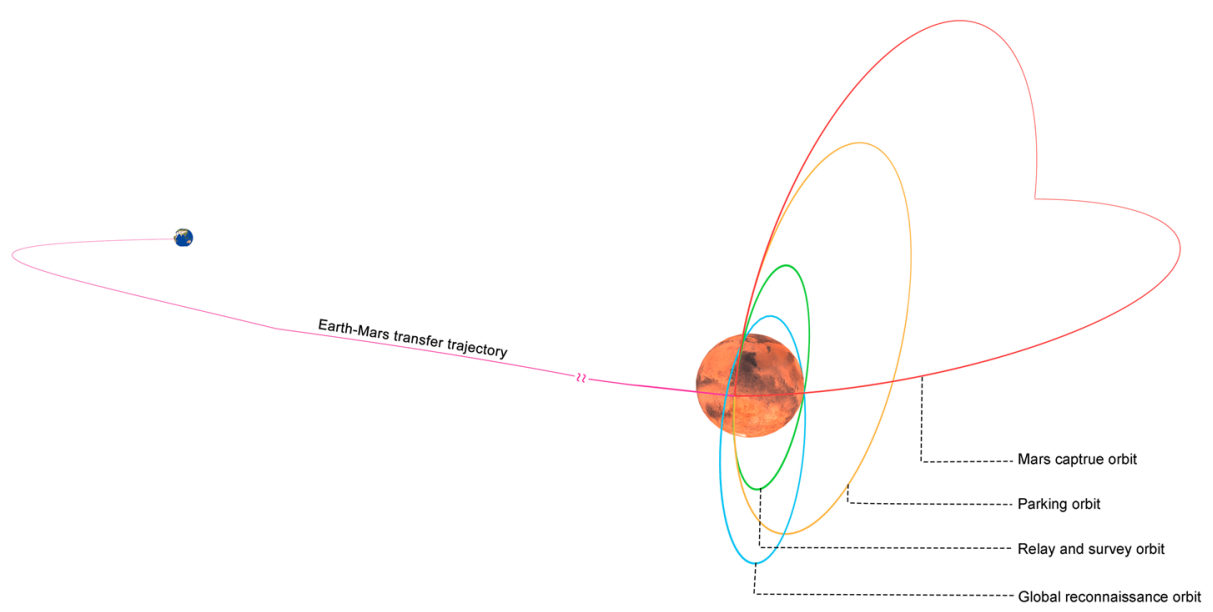

Fig. 1 China's first Mars Mission profile and flight orbit strategy
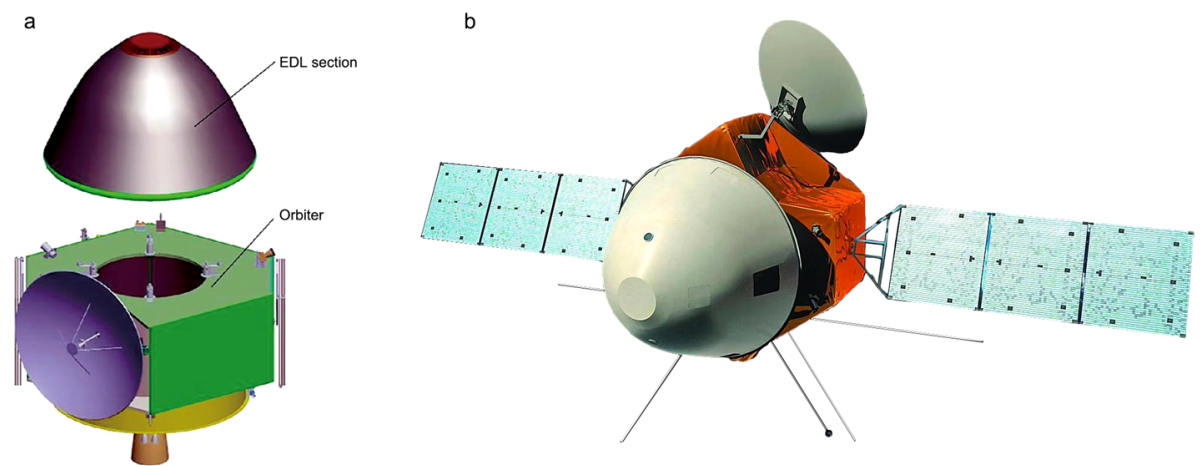

Fig. 2 Configuration of TW-1 probe. (a) The TW-1 probe consists of an orbiter and an EDL section in which is the rover and landing infrastructure. (b) is the illustration of TW-1 probe model. Its size is $13.6 \mathrm{~m} \times 4.2 \mathrm{~m} \times 1.6 \mathrm{~m}$ with solar panels open. There are two pairs of radar antennas with $5 \mathrm{~m}$ length, a magnetometer boom with $3 \mathrm{~m}$ length and communication antenna with $2.5 \mathrm{~m}$ diameter, respectively. (Redraw according to Ye et al. 2017)

\subsection{System Components}

The mission consists of five systems: probe, launch vehicle, launch site, telemetry track and command (TT\&C), and ground research and application system (GRAS).

The probe consists of an orbiter and an EDL section which is made up of an entry capsule, landing infrastructure and rover (Fig. 2). The orbiter transfers data to the Earth through $X$ band signal with code rate of $16 \mathrm{kbps}-4096 \mathrm{kbps}$. The communication between the orbiter and the rover are through UHF band and $\mathrm{X}$ band signals. The probe has been launched with Long March 5 carrier rocket at Wenchang launch site in Hainan province on July 23, 2020. The TT\&C system is responsible for the measurement and control of the probe. The GRAS includes a headquarters and three ground stations at Miyun, Wuqing and Kunming. Its responsibility involves the formulation of in-orbit scientific exploration plan, payloads 
operation, the receiving, processing, interpretation and management of scientific detection data, and the application and research of scientific data.

The Advanced Science Research Team was formed by China National Space Administration (CNSA) to participate in the research on scientific objectives of Mars exploration mission. An academic seminar had been held every year to promote the communication between engineering team and science community from 2017.

\subsection{Scientific Objectives}

According to the general plan of China's deep space exploration and the progress of international Mars exploration, the scientific objectives of China's first Mars exploration mission include the following. The objectives will focus on two scientific problems regarding the environment in which the life existed, and the origin and evolution of Mars and the solar system.

(1) To map the morphology and geological structure: to map the global topography and geomorphology, to obtain the high-precision topography of typical regions, and to study the formation and evolution of the Mars geological structure. Geology and topography will be investigated by context imaging at $100 \mathrm{~m} / \mathrm{px}$ resolution complemented by highresolution imaging of key selected areas at $0.5 \mathrm{~m} / \mathrm{px}$ resolution.

(2) To investigate the surface regolith characteristics and water-ice distribution: to investigate the regolith types, weathering and sedimentary characteristics and global distribution, to measure the subsurface structure, to search for the water and ice information, and to study the stratification structure of regolith profile. Subsurface structure and water ice distribution will be investigated by two sets of Radar on orbiter and rover. The orbiter subsurface penetrating radar sounding of the subsurface structure down to the depth of $100 \mathrm{~m}$ with vertical resolution of meter level will add the third dimension to the surface investigations. The rover subsurface penetrating radar sounding of the subsurface structure can down to the depth of $10 \mathrm{~m}$ and $3 \mathrm{~m}$ with vertical resolution of meter level and centimeter level, respectively.

(3) To analyze the surface material composition: to identify the rock types and the minerals on the Martian surface, and to analyze the mineral composition. The mineral and rock types and their distribution on the Mars' surface will be investigated by hyperspectral remote sensing in the wavelength range from 0.45 to $3.4 \mu \mathrm{m}$. The distribution of major mineral elements will be investigated by in-situ Laser-induced Breakdown Spectroscopy (LIBS) with the detection accuracy better than $10 \%$.

(4) To measure the ionosphere and the characteristics of the Martian climate and environment at the surface: to measure the space environment, the temperature, pressure and wind fields. To study structure, composition dynamics of the neutral atmosphere; aeronomy, plasma environment and escape; seasonal changes of surface weather. Interplanetary space and plasma environment will be investigated by Ion and Neutral Particle Analyzer, Energetic Particles Analyzer and Very Low Frequency Radio Receiver. Ion energy range is $5 \mathrm{eV}-25 \mathrm{KeV}$, neutral particle energy range is $50 \mathrm{eV}-3 \mathrm{KeV}$, electron energy range is $0.1-12 \mathrm{Mev}$, proton energy range is 2-100 Mev, and heavy ion energy range is 25-300 Mev. Very Low Frequency Radio receiver frequency range is $10 \mathrm{kHz}-10 \mathrm{MHz}$.

(5) To perceive the physical fields (electromagnetic, gravitational) and internal structure of Mars: to measure the Mars magnetic properties and study the early geological evolution history, the mass distribution and gravity field. The detection range of Mars 


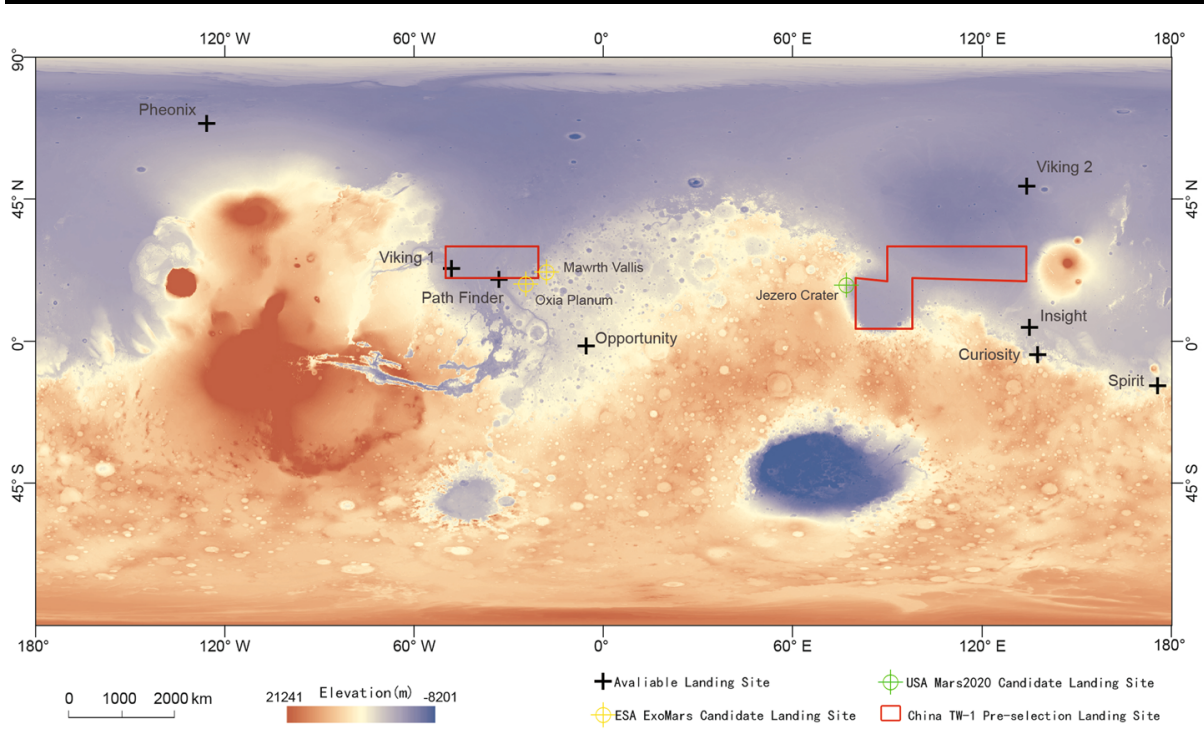

Fig. 3 Candidate landing areas of China's Mars Exploration Mission. Base image is from MOLA DEM (https://astrogeology.usgs.gov/search/details/Mars/GlobalSurveyor/MOLA/Mars_MGS_MOLA_DEM_ mosaic_global_463m)

space magnetic intensity is $\pm 10000 \mathrm{nT}$ with the resolution better than $0.01 \mathrm{nT}$. The detection range of Martian surface magnetic field measurement is $\pm 2000 \mathrm{nT}$ dynamic, and $\pm 65000 \mathrm{nT}$ compensation. The resolution is better than $0.01 \mathrm{nT}$.

The above five scientific objectives will be achieved by remote and in-situ investigations jointly. The investigations from orbit will focus on the integrated and comprehensive exploration of Mars, and to establish an overall scientific context of Mars. The investigations from rover will focus on the high precision and resolution detection and in situ analysis of the Mars key areas.

Through the synergistic exploration of the orbiter and the rover as well as simultaneous space-ground exploration, the Mars topography, regolith properties, material composition, water-ice distribution, ionosphere and magnetic field will be investigated.

\subsection{Candidate Landing Area}

Two landing areas for China's first Mars exploration mission are preselected based on the following engineering criteria and scientific objectives (Fig. 3).

Engineering criteria of landing site selection include (Ye et al. 2017):

(1) Latitude: landing area should be between $5-30{ }^{\circ} \mathrm{N}$;

(2) Altitude: the lower the better, the elevation of landing site should be at least $-2 \mathrm{~km}$;

(3) Slope: avoid steep slopes area, choose relative flat area;

(4) Surface condition: should avoid dusty area and choose area with less dust cover;

(5) Rock distribution: should avoid area of abundant rocks, and choose area with less amount of rocks;

(6) Local wind speed: landing area with lower wind speeds are preferred;

(7) Visibility requirements during the landing process: the EDL process should be scheduled on the side of Mars that is visible from Earth at the time of landing. 
Key scientific objectives required to be considered:

(1) Geology: the landing area should have as diverse geology as possible;

(2) Soil structure and water ice distribution: choose potential area that has the highest opportunity to find water ice or ground water;

(3) Surface elements, mineral, and rock distribution: choose potential area that has higher possibility to find diverse element, mineral and rocks;

(4) Magnetic field detection: choose the area favourable for Mars Magnetic field.

There are multiple rounds of selection during the landing area selection process to balance the technical feasibility and scientific interests. Firstly, landing areas meeting the strict criterion of engineering constraints would be selected and introduced. Then, the scientists would propose some interested landing sites from the selected areas according to the scientific objectives of the mission. After that, the proposed landing sites would be evaluated. In each round, the suggestion from the engineers and scientists will be thoroughly discussed.

(1) Preselected landing area 1 The primary landing area 1 is located in the Chryse Planitia plain, close to dihotomy boundary. The landing site of Viking-1 is located in the west, while the landing site of Pathfinder, ESA pre-selected Oxia Planum and Mawrth Vallis landing zones are located in the south. The topography shows there may be water-formed channels. Geologic units Hto (Hesperian transition outflow unit), 1Ht (Late Hesperian transition unit) and $\mathrm{lHl}$ (late Hesperian lowland unit) are close to the pre-selected area 1.

(2) Preselected landing area 2 The pre-selected area 2 is located partly in Isidis Planitia and partly in Utopia Planitia. Isidis Planitia is the third largest basin on Mars, formed in the Noachian geological era 3.9 billion years ago. This area is covered by Martian dust and brighter in telescope image, making it as a typical reflectance feature on the Martian surface. Geologic units $1 \mathrm{Hl}$ (late Hesperian lowland unit) and AHv (amazonian and Hesperian volcanic unit) are close to the preselected landing area 2. Landing site of ESA's Beagle 2 in the late Hesperian era is also located in this preselected landing area. The eastern side of landing area is located in the volcanic region, a transition zone from Hesperian to Amazonian, with relatively younger strata.

According to the current orbit design, we are more inclined to land on the surface of southern Utopia planitia, adjacent to the west of Elysium Mon, where many water/ice related landforms have been found such as domes/pitted cones, rampart crater, mound, and lava flow front. This landing area was selected because we aim to conduct scientific exploration regarding whether ancient ocean ever exist on the northern part of the Mars and the geological evolution history of the Mars volcanos.

\section{Payloads and Scientific Tasks}

\subsection{Payloads on the Orbiter}

Remote sensing is an important exploration method which helps to obtain the global exploration data and to construct the global conception for Mars studies. Therefore, the investigations from orbit is the preferred at the beginning stage of planetary exploration.

According to the scientific objectives of TW-1 mission, the experiences of international Mars explorations and the scientific research progress, as well as the development of the China's aerospace science and technology, the scientific objectives of Mars orbiter include the following five aspects: to analyze Martian ionosphere, plasma environment and escape 
Table 2 The designated payloads for the orbiter investigations and their corresponding scientific tasks

\begin{tabular}{|c|c|}
\hline Scientific tasks & Payloads \\
\hline \multirow{4}{*}{$\begin{array}{l}\text { Martian ionosphere, plasma environment and } \\
\text { escape processes }\end{array}$} & Mars Orbiter Magnetometer (MOMAG) \\
\hline & Mars Ion and Neutral Particle Analyzer (MINPA) \\
\hline & Mars Energetic Particles Analyzer (MEPA) \\
\hline & $\begin{array}{l}\text { Very Low Frequency Radio Receiver (VLFRR) of } \\
\text { Mars Orbiter Scientific Investigation Radar (MOSIR) }\end{array}$ \\
\hline Martian surface and subsurface water-ice & Mars Orbiter Scientific Investigation Radar (MOSIR) \\
\hline \multirow[t]{3}{*}{ Martian regolith types distribution and structure } & Mars Orbiter Scientific Investigation Radar (MOSIR) \\
\hline & Mars Mineralogical Spectrometer (MMS) \\
\hline & Moderate Resolution Imaging Camera (MoRIC) \\
\hline \multirow{2}{*}{$\begin{array}{l}\text { Martian topography characteristic and their } \\
\text { changes }\end{array}$} & Moderate Resolution Imaging Camera (MoRIC) \\
\hline & High Resolution Imaging Camera (HiRIC) \\
\hline Martian surface material composition & Mars Mineralogical Spectrometer (MMS) \\
\hline
\end{tabular}

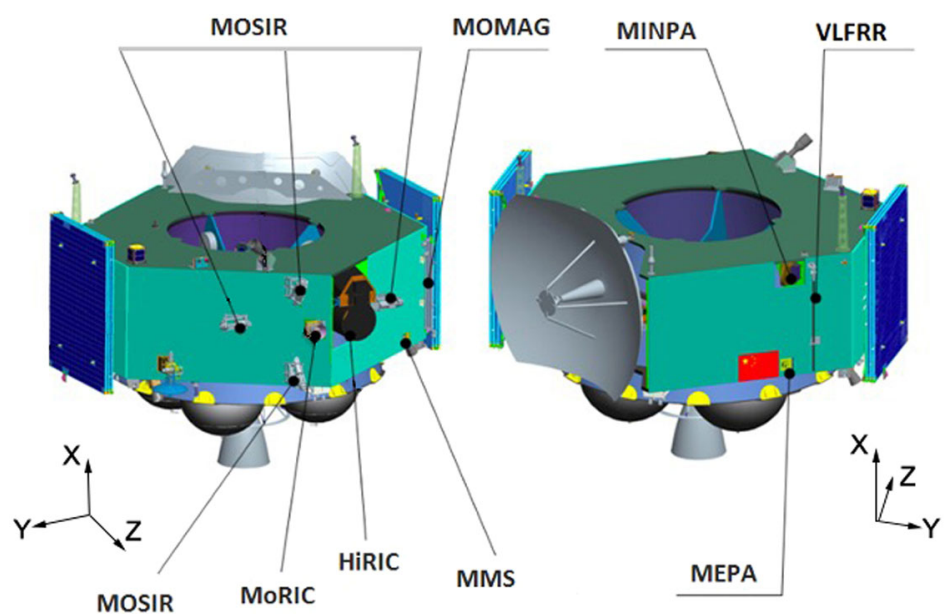

Fig. 4 The configuration and layout of payloads onboard Orbiter. The orbiter coordinate system X-axis, Yaxis, and Z-axis form a right-hand system, with the $\mathrm{X}$-axis is the flight direction and the Z-axis is direct toward the Mars at the periareon. Cameras (MoRIC and HiRIC), spectrometer (MMS), radar (MOSIR), magnetometer (MOMAG) are installed in the Z-axis direction. MINPA, MEPA and VLFRR are installed in the negative $\mathrm{Z}$-axis direction

processes, to investigate Martian surface and subsurface water-ice, to investigate Martian regolith types distribution and structure, to map Martian topography characteristic and their changes, and to characterize Martian surface material composition.

To achieve the scientific objectives of orbiter investigation, the Mars orbiter is equipped with seven types of payloads including moderate resolution imaging camera, high resolution imaging camera, mars orbiter scientific investigation radar, Mars mineralogical spectrometer, Mars orbiter magnetometer, Mars ion and neutral particle analyzer and Mars energetic particles analyzer (Table 2, Fig. 4). The main technical parameters of these payloads are shown in Table 3. 
Table 3 Payload configuration and main technical parameters of TW-1 Mars Orbiter

\begin{tabular}{|c|c|}
\hline Payloads & Technical parameters \\
\hline \multirow{6}{*}{$\begin{array}{l}\text { Moderate } \\
\text { Resolution } \\
\text { Imaging Camera } \\
\text { (MoRIC) }\end{array}$} & (1) Color: RGB \\
\hline & (2) Imaging Band: Visible \\
\hline & (3) Spatial resolution: 100 m@400 km \\
\hline & (4) Frame Width: 400 km@400 km \\
\hline & (5) Pixel: $4096 \times 3072$ \\
\hline & (6) Field of View: $53.1^{\circ} \times 41.1^{\circ}\left(\right.$ diagonal $\left.64^{\circ}\right)$ \\
\hline \multirow{4}{*}{$\begin{array}{l}\text { High Resolution } \\
\text { Imaging Camera } \\
\text { (HiRIC) }\end{array}$} & (1) Resolution (@265 km altitude) \\
\hline & Panchromatic: better than $2.5 \mathrm{~m}$, in key areas better than $0.5 \mathrm{~m}$ \\
\hline & Color: better than $10 \mathrm{~m}$, in key areas better than $2.0 \mathrm{~m}$ \\
\hline & (2) Swath Width: 9 km@265 km \\
\hline \multirow{11}{*}{$\begin{array}{l}\text { Mars Orbiter } \\
\text { Scientific } \\
\text { Investigation } \\
\text { Radar (MOSIR) }\end{array}$} & (1) Mars subsurface structure and water ice exploration \\
\hline & Frequency: $10 \mathrm{MHz}-20 \mathrm{MHz}, 30 \mathrm{MHz}-50 \mathrm{MHz}$ \\
\hline & Polarization: $\mathrm{HH}, \mathrm{HV}$ \\
\hline & Transmitter power: $\geq 100 \mathrm{~W}$ \\
\hline & Receiver sensitivity: $\leq-87 \mathrm{dBm}$ \\
\hline & $\begin{array}{l}\text { Detecting depth: Mars subsurface structure, } \sim 100 \mathrm{~m} \text { (regolith, } \varepsilon \gamma=3.0-4.0 \text { ), Mars } \\
\text { polar ice, } \sim 1000 \mathrm{~m} \text { (ice, } \varepsilon \gamma=3.0 \text { ) }\end{array}$ \\
\hline & Thickness resolution: meter level \\
\hline & (2) Ranging precision: better than $10 \mathrm{~m}$ \\
\hline & (3) Interplanetary very low frequency radio spectrum detection \\
\hline & VLF receiver frequency: $10 \mathrm{kHz}-10 \mathrm{MHz}$ \\
\hline & $\begin{array}{l}\text { VLF receiver resolution: better than } 1 \mathrm{KHz}(10 \mathrm{KHz}-500 \mathrm{KHz}) \text {, better than } 20 \mathrm{KHz} \\
(500 \mathrm{KHz}-10 \mathrm{MHz})\end{array}$ \\
\hline \multirow{3}{*}{$\begin{array}{l}\text { Mars } \\
\text { Mineralogical } \\
\text { Spectrometer } \\
\text { (MMS) }\end{array}$} & (1) Spectral range $(\mu \mathrm{m})$ : \\
\hline & $\begin{array}{l}\text { Visible-near infrared, } 0.45-1.0 \mu \mathrm{m} \text {, intermediate infrared and near-infrared, } \\
1.00-3.40 \mu \mathrm{m}\end{array}$ \\
\hline & $\begin{array}{l}\text { (2) Spectral resolution: visible-near infrared,better than } 10 \mathrm{~nm} \text {, intermediate infrared and } \\
\text { near-infrared, better than } 12 \mathrm{~nm} @ 1.0 \mu \mathrm{m}-2.0 \mu \mathrm{m} \text {, better than } 25 \mathrm{~nm} @ 2.0 \mu \mathrm{m}-3.4 \mu \mathrm{m} \text {. }\end{array}$ \\
\hline \multirow{5}{*}{$\begin{array}{l}\text { Mars Orbiter } \\
\text { Magnetometer } \\
\text { (MOMAG) }\end{array}$} & (1) Measurement range: $\pm 10000 \mathrm{nT}$ \\
\hline & (2) Resolution: better than $0.01 \mathrm{nT}$ \\
\hline & (3) Precision: $0.1 \mathrm{nT}$ \\
\hline & (4) Noise level: $\leq 0.01 \mathrm{nT} / \sqrt{\mathrm{Hz}}$ \\
\hline & (5) Stability: $\leq 0.01 \mathrm{nT} /{ }^{\circ} \mathrm{C}$ \\
\hline \multirow{12}{*}{$\begin{array}{l}\text { Mars Ions and } \\
\text { Neutral Particle } \\
\text { Analyzer } \\
\text { (MINPA) }\end{array}$} & (1) Low energy ions: \\
\hline & Energy range: $5 \mathrm{eV}-25 \mathrm{KeV}$ \\
\hline & Energy resolution $(\Delta E / E): 15 \%$ \\
\hline & Mass: 1-70 amu \\
\hline & Field of view: $90^{\circ} \times 360^{\circ}$ \\
\hline & Angular resolution: $11.2^{\circ} \times 22.5^{\circ}$ \\
\hline & (2) Low energy neutral particles: \\
\hline & Energy range: $50 \mathrm{eV}-3 \mathrm{KeV}$ \\
\hline & Energy resolution $(\Delta E / E): 100 \%$, Mass: $1-32 \mathrm{amu}$ \\
\hline & Field of view: $15^{\circ} \times 160^{\circ}$ \\
\hline & Angular resolution: $10^{\circ} \times 25^{\circ}$ \\
\hline & Time resolution: $4 \mathrm{~s}$ \\
\hline
\end{tabular}


Table 3 (Continued)

\begin{tabular}{ll}
\hline Payloads & Technical parameters \\
\hline Mars Energetic & (1) Energy range: \\
Particles & Electronic: $0.1-12 \mathrm{MeV}$ \\
Analyzer & Proton: $2-100 \mathrm{MeV}$ \\
(MEPA) & $\alpha$-particle, heavy ion: $25-300 \mathrm{MeV}$ \\
& (2) Energy resolution $(\Delta E / E): 15 \%$ \\
& (3) Flux range: $0-10^{5} \mathrm{~cm}^{-2} \mathrm{~s}^{-1}$ \\
& (4) Elementary composition: $\mathrm{H}-\mathrm{Fe}(1 \leq Z \leq 26)$ \\
& (5) Heavy ion mass resolution $(\Delta m / m):$ \\
& $\leq 25 \%(Z \leq 9,25-300 \mathrm{MeV})$ \\
& $\leq 25 \%(10 \leq Z \leq 26,100-300 \mathrm{MeV})$ \\
& $\leq 60 \%(10 \leq Z \leq 26,25-100 \mathrm{MeV})$ \\
& (6) Field of view: $60^{\circ}$ \\
& (7) Time resolution: $4 \mathrm{~s}$ (proton, electron, alpha particle), 60 s (heavy ion)
\end{tabular}

(1) Analyze Martian ionosphere, plasma environment and escape processes The orbiter is equipped with Mars orbiter magnetometer, Mars ion and neutral particle analyzer, Mars energetic particles analyzer and very low frequency radio receiver to explore the ionosphere and interplanetary environment. Mars orbiter magnetometer is used to map Martian magnetic field. The Mars ion and neutral particle analyzer measures the flux of ions in space environment, distinguishes the main ions and obtains their physical parameters such as the density, velocity and temperature. In addition, it measures the flux of neutral energy particles and distinguishes the main neutral particle components such as $\mathrm{H}, \mathrm{He}$ and $\mathrm{O}$. Mars energetic particles analyzer obtains the energy spectrum, flux and elemental composition of energy electrons, protons, $\alpha$ particles and ions. Very low frequency radio receivers acquire the very low frequency radio spectrum data in the interplanetary space during the cruise phase.

A highly elliptical orbit will be adopted by the mission with a periareon of $265 \mathrm{~km}$ where the orbit enters the Mars ionosphere $(110 \mathrm{~km}-400 \mathrm{~km})$ and an apoareon of $11900 \mathrm{~km}$ which crosses the complex and variable magnetic field boundaries such as the bow shock wave (towards the sun), the magnetosheath layer, the boundary of the magnetic accumulation zone, the magnetic accumulation zone and the induced magnetic tail (back of the sun). It is expected to obtain the space magnetic field survey data at 2.8-4.3 Rm (Radius of Mars) to fill the gap in existing Mars exploration (MGS/MAVEN) in the far magnetic tail region, and to partially fill the gap of observation in the position of bow shock wave. New data of the ionosphere ions of $5 \mathrm{eV}$-several $\mathrm{KeV}$ will be obtained to fill in the blank of $50 \mathrm{eV}-3 \mathrm{KeV}$ ions detection of MAVEN ionosphere mode.

(2) Investigate Martian surface and subsurface water-ice The orbiter is equipped with Mars orbiter scientific investigation radar to investigate the Martian surface and subsurface waterice. It aims to explore water-ice by means of the dual-polarization echo characteristics of radar. When the radar is below the $800 \mathrm{~km}$ orbital altitude during the Mars-orbiting phase, the altimetry mode, ionospheric detection mode and subsurface detection mode will be used.

(3) Investigate Martian regolith types distribution and structure The orbiter is equipped with Mars orbiter scientific investigation radar and Mars mineralogical spectrometer. The 
Table 4 Scientific tasks and the designated payloads for in-situ exploration

\begin{tabular}{ll}
\hline Scientific tasks & Payloads \\
\hline Surface morphology and geology & Navigation and Terrain Camera (NaTeCam) \\
Subsurface structure and water ice distribution & Mars Rover Penetrating Radar (RoPeR) \\
Surface elemental composition and mineralogy & Mars surface Composition Detector (MarSCoDe) \\
Magnetic field & Multispectral Camera (MSCam) \\
Atmospheric properties and meteorology & Mars Rover Magnetometer (RoMAG) \\
\hline
\end{tabular}

Mars orbiter scientific investigation radar data, combined with the optical image and compositional information acquired by Mars mineralogical spectrometer, will be used to investigate the distribution of regolith types and subsurface structure of Mars.

(4) Map Martian topography characteristic and their changes The orbiter is equipped with moderate resolution imaging camera, high resolution imaging camera and Mars orbiter scientific investigation radar to characterize the topographic and geomorphological features of Mars and their changes. Moderate resolution imaging camera can obtain the global geomorphic data with a spatial resolution of about $100 \mathrm{~m}$. The images overlap along the flight direction is up to $60 \%$, and the side overlap between adjacent orbits is up to $15 \%$, satisfying the need of three-dimensional imaging. High resolution imaging camera can acquire highresolution images and perform detailed surveys on key areas and landing area, and obtain the landform data with spatial resolution of $0.5 \mathrm{~m}$. The elevation can be measured by the Mars orbiter scientific investigation radar. Based on these three payloads, the formation process of Mars geological features, such as geomorphology of landing site, flow, volcano, erosion, impact crater and polar glacier will be studied.

(5) Characterize Martian surface material composition The orbiter is equipped with Mars mineralogical spectrometer, which utilizes the visible and near infrared imaging spectrometer with detection wavelengths ranging from 0.45 to $3.4 \mu \mathrm{m}$ to investigate and analyze the Martian surface composition.

\subsection{Payloads on the Rover}

The mission will combine remote sensing and detailed in-situ exploration to advance our scientific understanding of Mars. The rover will undertake the following four scientific tasks in landing sites: to map morphology and geology, to investigate subsurface structure and possible water-ice, to analyze surface elements, minerals and rock types, and to measure atmosphere physical characteristics and surface environment.

In order to complete these scientific tasks, the Mars rover is equipped with six instruments (Table 4, Fig. 5) including the Mars surface composition detector, multispectral camera, navigation and terrain camera, Mars rover penetrating radar, Mars rover magnetometer, and Mars meteorological instrument. The technical parameters of these payloads are shown in Table 5.

(1) Surface morphology and geology of landing sties High-resolution 3D panoramic images will be obtained with two navigation topography cameras onboard the rover. These data will be used to construct topography maps, extract parameters such as slope, undulation 


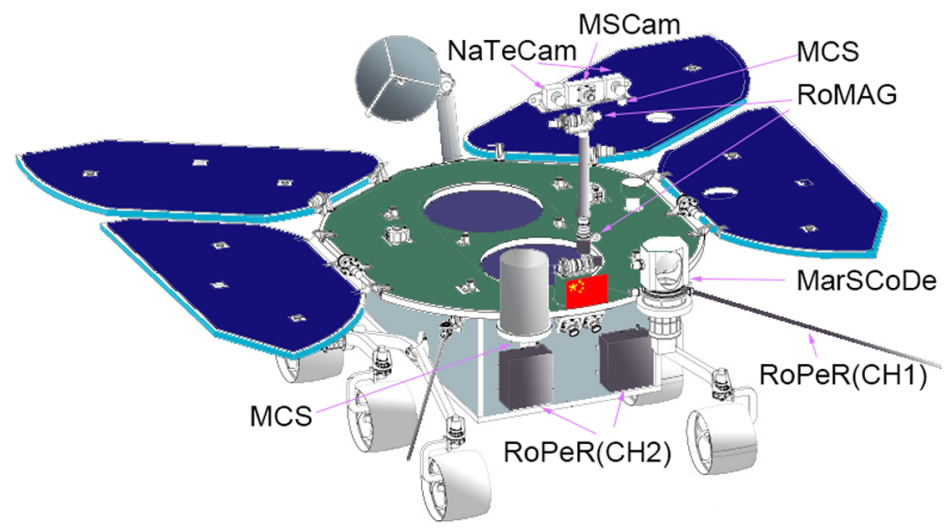

Fig. 5 The configuration and layout of payloads onboard the Rover. The NaTeCams are binocular stereo cameras. NaTeCams and MSCam are mounted on the mast. Two tri-axial magnetometers (RoMAG) are mounted on the top and bottom of the mast, respectively. The distance between them is $67.5 \mathrm{~cm}$. The RoPeR two low frequency channel $(\mathrm{CH} 1)$ antennas are respectively mounted on two bottom sides of the top board of the rover. The length of each $\mathrm{CH} 1$ antenna is $1350 \mathrm{~mm}$. The RoPeR two high frequency channel $(\mathrm{CH} 2)$ antennas are mounted on the front board of the rover. The wind sensor and microphone unit of MCS are mounted on the mast. The air temperature and pressure sensor unit of MCS is mounted at the bottom of the UHF band relay antenna. MarSCode is mounted on the left top board of the rover

and roughness, investigate geological structures, and conduct comprehensive analysis on the geological structure of the surface parameters. Based on the investigated topography, geomorphology and geological structures, the local morphologic and geological evolution models will be established.

(2) Subsurface structure and water-ice distribution of landing sties The full-polarization radar on the rover is used for the first time, which in combination with other payloads on the orbiter can further enhance the depth of scientific research of subsurface structure and possible water-ice.

(3) Surface elemental composition and mineralogy of landing sties The elements, minerals and rocks are studied in details using the Mars surface composition detector and multispectral camera. Combined with water related landscape such as ancient lake, ancient river and alluvial island, weathering formed minerals will be searched such as carbonate minerals or hematite, layered silicate, hydrated sulfate, and perchloric minerals. Metamorphism effect of water on these minerals will be investigated to establish the relationship between Martian surface water environment and secondary mineral types, and to search for historical environmental conditions for the presence of liquid water.

(4) Magnetic field, atmospheric properties and meteorology of landing sties The fine-scale structures of crustal magnetic field is obtained with Mars rover magnetometer based on mobile measurements on the Martian surface. Combining with orbiter observation, the ionospheric conductivity by inverting the ionospheric dynamo current will be studied. In addition, we will explore the local interior structure using magnetic field variations.

The temperature, pressure, wind velocity and direction of the surface atmosphere, and sounds will be measured with Mars meteorological measuring instrument. 
Table 5 Payload configuration and main technical parameters of Mars rover

\begin{tabular}{ll}
\hline Payloads & Main technical parameters \\
\hline $\begin{array}{l}\text { Navigation and } \\
\text { Terrain Camera }\end{array}$ & (1) Color: RGB \\
(NaTeCam) & (3) Noctral range: visible \\
& (4) Pixel: $2048 \times 2048$ \\
Multispectral & (1) Spectral range (nm): there are 9 bands, which are $480(20), 525(20), 650(12)$, \\
Camera & 700(15), $800(25), 900(30), 950(50), 1000(50)$, and panchromatic \\
(MSCam) & The figures in brackets are the filters bandpasses (full width at half maximum) \\
& (2) Color: multi-spectral \\
& (3) Normal imaging distance: $1.5 \mathrm{~m}-\infty$ \\
& (4) Pixel: $2048 \times 2048$
\end{tabular}

Mars Rover

Penetrating Radar (RoPeR)

Mars surface Composition Detector (MarSCoDe)

Mars Rover Magnetometer (RoMAG)

Mars Climate Station (MCS)
(1) The first channel (CH1):

Frequency: 15-95 MHz

Polarization: $\mathrm{HH}$

Penetration thickness: meter level

Detection depth: $\geq 100 \mathrm{~m}$ (ice, $\varepsilon r=3.0$ ), $\geq 10 \mathrm{~m}$ (regolith, $\varepsilon r=3.0-4.0$ )

(2) The second channel ( $\mathrm{CH} 2)$ :

Frequency: 450-2150 MHz

Polarization: $\mathrm{HH}, \mathrm{HV}, \mathrm{VH}, \mathrm{VV}$

Penetration thickness: centimeter level

Detection depth: $\geq 10 \mathrm{~m}$ (ice, $\varepsilon r=3.0$ ), $\geq 3 \mathrm{~m}$ (regolith, $\varepsilon r=3.0-4.0$ )

(1) LIBS detection

Element type: no less than 10 elements ( $\mathrm{Si}, \mathrm{Al}, \mathrm{Fe}, \mathrm{Mg}, \mathrm{Ca}, \mathrm{Na}, \mathrm{O}, \mathrm{C}, \mathrm{H}, \mathrm{Mn}, \mathrm{Ti}, \mathrm{S}$, etc.) Detection distance: 2-5 m (best detection distance), with the largest distance of $10 \mathrm{~m}$

(2) Microscopic camera

Image resolution: $\leq 100 \mu \mathrm{rad}(0.20 \mathrm{~mm} @ 2 \mathrm{~m}, 0.50 \mathrm{~mm} @ 5 \mathrm{~m})$

Field of view: $\geq 1 \mathrm{mrad}$

Short-wave infrared spectral detection

Spectral range: $850-2400 \mathrm{~nm}$

Spectral resolution: $\leq 12 \mathrm{~nm}$

Band: no less than 130 bands

(1) Measurement range: $\pm 2000 \mathrm{nT}$ dynamic; $\pm 65000 \mathrm{nT}$ compensation

(2) Resolution: better than $0.01 \mathrm{nT}$

(3) Precision: $0.1 \mathrm{nT}$

(4) Noise level: $\leq 0.01 \mathrm{nT} / \sqrt{\mathrm{Hz}}$

(5) Stability: $\leq 0.01 \mathrm{nT} /{ }^{\circ} \mathrm{C}$

(6) sampling rate: $1 \mathrm{~Hz}, 16 \mathrm{~Hz}, 32 \mathrm{~Hz}, 128 \mathrm{~Hz}$

(1) Temperature: range $-120{ }^{\circ} \mathrm{C}-+50{ }^{\circ} \mathrm{C}$; resolution $0.1{ }^{\circ} \mathrm{C}$;

(2) Air pressure: range 1-1500 $\mathrm{Pa}$; resolution $0.1 \mathrm{~Pa}$;

(3) Wind speed: range $0-70 \mathrm{~m} / \mathrm{s}$; resolution $0.5 \mathrm{~m} / \mathrm{s}$;

(4) Wind direction: range $0-360^{\circ}$; resolution $5^{\circ}$;

(5) Sound: frequency range: $20 \mathrm{~Hz}-2.5 \mathrm{kHz}, 2.5 \mathrm{kHz}-20 \mathrm{kHz}$; sensitive: better than $50 \mathrm{mV} / \mathrm{Pa}$; dynamic range: $\geq 90 \mathrm{~dB}$ 


\section{Preliminary Scientific Investigation Plan}

\subsection{Scientific Investigation Plan of the Orbiter}

The orbiter will begin scientific investigation during the Earth-Mars transfer. The rover will be released after Mars orbit insertion and 2-3 months of the orbit adjustment in the parking orbit. After that, the orbiter performs maneuver, enters relay orbit, communicates with the rover, and conduct scientific exploration at the same time. After 90 sols of the rover mission, the orbiter enters the reconnaissance orbit for the orbiting investigations and rover data relay. The scientific investigation plans of the orbiter are presented in Table 6.

The payloads of the orbiter do not work in the launch phase, capture phase, and off-orbit landing phase.

Earth-Mars transfer orbit Mars orbiter scientific investigation radar (very low frequency detection), Mars ions and neutral particle analyzer, and Mars energetic particle analyzer continuously operate during Earth-Mars transfer. Moderate resolution imaging camera will work at selected time to image the Earth, the Moon and Mars. Other payloads will choose time to carry out self-check.

Mars parking orbit, relay and survey orbit After captured by Mars, the payloads on obiter will start on-orbit test work. The moderate resolution imaging camera, high resolution imaging camera and Mars mineralogical spectrometer will focus on investigation of pre-selected landing areas. The rover will start a 90 sols in-situ exploration after the lander is released. The orbiter will perform orbit maneuver and enter one Martian year global reconnaissance orbit after the rover works on Mars for 90 sols.

Global reconnaissance orbit Moderate resolution imaging camera, high resolution imaging camera, Mars orbiter scientific investigation radar and the Mars mineralogical spectrometer will operate below the $800 \mathrm{~km}$ altitude. The Mars orbiter magnetometer, Mars ion and neutral particle analyzer and the Mars energetic particles analyzer work continuously.

\subsection{Scientific Investigation Plan of the Rover}

The working life of the rover on the Martian surface is designed to be 90 sols. After landing, the rover will extend its solar panels, establish direction control of the Earth-point antenna and report its initial status. The orbiter will be located in a relay and survey orbit to support the rover's scientific investigation of Mars. The Mars rover penetrating radar works during the roving. The Mars surface composition detector, Multispectral Camera, Navigation and Terrain Camera begin to work when the rover stops after reaching the study target. Both the Mars rover magnetometer and Mars climate station work during the roving or when it stops.

Every three sols are defined as one operation period. The basic process of each operation period is as following (Fig. 6):

(1) On the first sol of operations period, the Navigation and Terrain Camera obtains the stereo image pairs of the study target and downlinks them for operations plan of the rover and the selection of the next study target;

(2) On the second sol of operations period, each payload performs scientific exploration on the study target according to the operations plan, and downlinks the data;

(3) On the third sol, the rover moves to the next study target, and Mars Rover Penetrating Radar, Mars Climate Station work until it arrives at the next study target. The rover payloads complete a operations period and downlinks the data. 
Table 6 Scientific investigation plans by the orbiter payloads

\begin{tabular}{lll}
\hline Payloads & $\begin{array}{l}\text { Earth-Mars transfer } \\
\text { orbit }\end{array}$ & $\begin{array}{l}\text { Mars parking orbit, relay } \\
\text { and survey orbit }\end{array}$ \\
\hline
\end{tabular}

MoRIC (1) Self-check once a month

(2) Select the time to start working, imaging the Earth, the Moon and Mars

HiRIC

Self-check once a month

MOSIR After the separation of satellite and rocket, the VLF antenna selects time to explore the interplanetary radio

MMS Self-check once at selected time

MOMAG Self-check twice at selected time
(1) On-orbit calibration at the apoareon once a month, and data downlink (2) 3D images of the landing area from periareon

(1) Self-check once a month

(2) 3D images of the landing area from periareon

(1) Select time to deploy the radar antenna including the transmit antenna and receive antenna

(2) Subsurface investigations of the landing area from periareon

(3) Subsurface investigations of polar ice caps and other areas of interest when the orbit is higher than $800 \mathrm{~km}$ and the requirements are satisfied

(1) Self-check once at selected time

(2) Spectral observation of the landing area from periareon

(3) On-orbit calibration at the apoareon

Select time to deploy the boom, same working mode as that used in the global reconnaissance orbit
(1) On-orbit calibration at the apoareon once a month

(2) Images are captured when the orbit altitude is below $800 \mathrm{~km}$ and sun elevation angle is larger than 5 degree, with the average work time of 26 minutes and the imaging interval of $20 \mathrm{~s}-66 \mathrm{~s}$

(3) In order to achieve the coverage, the images can be obtained with off-nadir pointing of the spacecraft

(1) High resolution imaging when the orbit altitude is below $800 \mathrm{~km}$ and sun elevation angle is larger than 10 degree (2) In order to achieve the coverage, the images can be obtained with off-nadir pointing of the spacecraft

(1) Calibration of equipment lasts about $70 \mathrm{~s}$ before the probe enters the periareon section above the orbit altitude of $800 \mathrm{~km}$

(2) After the calibration, the radar starts to work with the mode selected from the on-orbit working mode list (with average working time of 26 minutes)

(1) Continuous multi-unit spectral observation. The spectral data are obtained at an altitude below $800 \mathrm{~km}$, and MMS work for 21 minutes each time

(2) Investigation of interested regions

(3) On-orbit calibration at the apoareon and work once to twice each month

Works continuously

(1) Work with the $32 \mathrm{HZ}$ sampling rate $0.5 \mathrm{~h}$ before and after reaching the apoareon

(2) Work with the $32 \mathrm{HZ}$ sampling rate $1 \mathrm{~h}$ before and after reaching the periareon

(3) Work with the $1 \mathrm{HZ}$ sampling rate in other orbit sections 
Table 6 (Continued)

\begin{tabular}{|c|c|c|c|}
\hline Payloads & $\begin{array}{l}\text { Earth-Mars transfer } \\
\text { orbit }\end{array}$ & $\begin{array}{l}\text { Mars parking orbit, relay } \\
\text { and survey orbit }\end{array}$ & Global reconnaissance orbit \\
\hline MINPA & $\begin{array}{l}\text { After entering the } \\
\text { Earth-Mars transfer } \\
\text { orbit, the } \\
\text { high-voltage } \\
\text { debugging starts in } \\
\text { the first month, after } \\
\text { which the payload } \\
\text { carries out the } \\
\text { interplanetary solar } \\
\text { wind detection } \\
\text { continuously }\end{array}$ & $\begin{array}{l}\text { (1) After entering the } \\
\text { parking orbit, working } \\
\text { continuously, and turned } \\
\text { off before the separation } \\
\text { of the lander } \\
\text { (2) Work continuously } \\
\text { after entering the relay } \\
\text { and survey orbit and } \\
\text { powers off before the end } \\
\text { of the mission }\end{array}$ & $\begin{array}{l}\text { Works continuously } \\
\text { (1) Work with the ionospheric mode } \\
\text { below the orbit altitude of } 800 \mathrm{~km} \\
\text { (2) Work with the default mode above } \\
800 \mathrm{~km} \\
\text { (3) Switch to magnetic-tail mode } 30 \\
\text { minutes before the apoareon and switch } \\
\text { back to the default mode } 30 \text { minutes } \\
\text { after the apoareon as required }\end{array}$ \\
\hline MEPA & Continuous working & Continuous working & Continuous working \\
\hline
\end{tabular}

Table 7 Scientific data products categorization

Data level Data description

Level 0 Level 0A

Source packet data that are generated after ground demodulation, frame synchronization, descrambling, channel decoding, demultiplexing and other processing of the data sent back from a spacecraft and received at a single ground station for each payload

Level OB Data collected by each payload, which are generated after package structure removing and decompressing (where applicable) of the source packet data; those source packet data are, on the basis of Level 0A, generated after combining (where applicable), sorting and deduplicating of the data from multiple ground receiving stations

Level 1 Level 1 Data that are generated, on the basis of Level 0B, after numerically converting temperature, voltage, current and other instrument parameters, and reorganizing according to observation periods

Level 2 Level 2A/2B/2C Data in physical units that are generated, on the basis of level 1, after applying calibration, and provide geometric positioning information. Level 2 data products are divided into several sub-levels, level 2A, level $2 \mathrm{~B}$ and level 2C (where applicable)

\subsection{Data Products}

Focusing on the five scientific objectives of China's first Mars exploration mission, the orbiter is equipped with 7 instruments and the rover is equipped with 6 instruments for scientific exploration. The obtained exploration data will be preprocessed according to the following levels (Table 7). Level 0 data products are stored in binary file format, while level 1 and level 2 data products are stored in standard PDS4.0 format. Levels 3 is high level science maps, including digital orthophoto maps, digital elevation models and mineralogical maps, etc.

GRAS and the instruments teams will expect to follow the data release policy proposed by CNSA based on an official 5-6 months' proprietary period that is used by the teams to validate, calibrate, and perform preliminary scientific data exploration. After all the proce- 


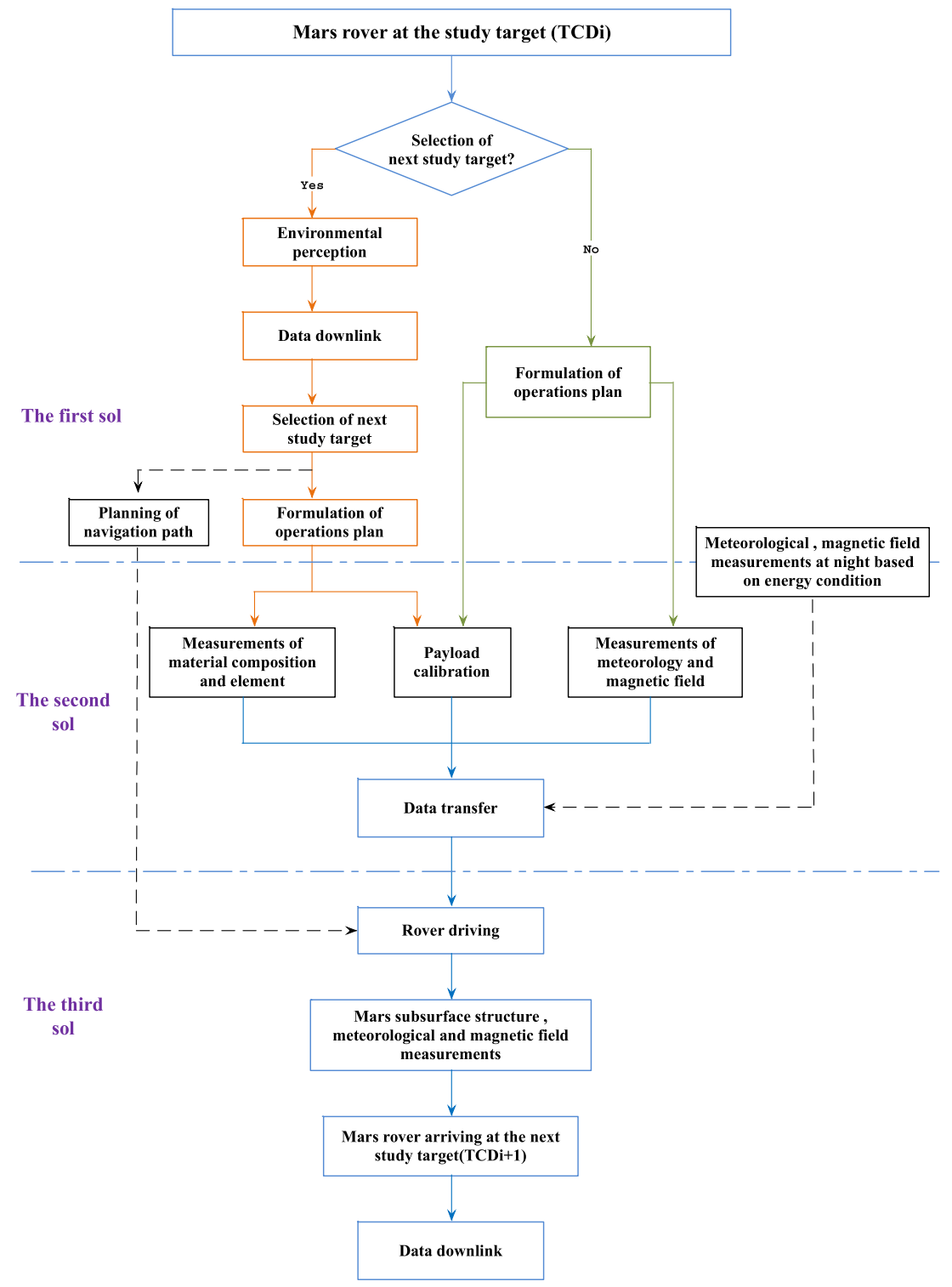

Fig. 6 Process of rover scientific investigation

dures are complete, the data will be released to the scientific community from the website (http://moon.bao.ac.cn/index_en.jsp).

\subsection{Expected Scientific Achievements}

According to the preliminary scientific investigation plan, the expected scientific achievements of China's first Mars exploration mission are as following (Table 8). 
Table 8 Expected scientific achievements and scientific objectives of China's first Mars exploration mission

\begin{tabular}{|c|c|c|c|}
\hline Payloads & Expected scientific data & Expected scientific achievements & Scientific objectives \\
\hline MoRIC & $\begin{array}{l}\text { 1. Global orthophoto images } \\
\text { with spatial resolution of } \\
66 \mathrm{~m}-200 \mathrm{~m} / \text { pixel } \\
\text { 2. Global DEM with spatial } \\
\text { resolution of } \\
200 \mathrm{~m}-600 \mathrm{~m} / \text { pixel }\end{array}$ & $\begin{array}{l}\text { Global topography and } \\
\text { geomorphology as well as their } \\
\text { variations, such as polar cap, sand } \\
\text { dunes, layered deposit }\end{array}$ & $\begin{array}{l}\text { To map Martian } \\
\text { topography, landform and } \\
\text { their changes, and to } \\
\text { obtain the basic } \\
\text { information on Mars } \\
\text { evolution }\end{array}$ \\
\hline HiRIC & $\begin{array}{l}\text { The key area images with } \\
\text { spatial resolution of } \\
0.5 \mathrm{~m}-1.5 \mathrm{~m} / \mathrm{pixel}\end{array}$ & $\begin{array}{l}\text { Detailed investigation of key areas, } \\
\text { such as geomorphology of flow, } \\
\text { volcano, erosion, impact crater and } \\
\text { polar glacier }\end{array}$ & \\
\hline NaTeCam & $\begin{array}{l}\text { Stereo images, panoramic } \\
\text { mosaic and 3D topographic } \\
\text { map of landing areas }\end{array}$ & $\begin{array}{l}\text { 1. Geomorphology of landing areas } \\
\text { 2. High-resolution digital elevation } \\
\text { models of landing areas } \\
\text { 3. Geology characteristic }\end{array}$ & \\
\hline RoPeR & $\begin{array}{l}\text { 1. Acquire subsurface echo } \\
\text { data of low-frequency channel } \\
\text { radar }(15-95 \mathrm{MHz}) \text { and } \\
\text { high-frequency channel } \\
\text { full-polarization radar } \\
\text { ( } 450-2150 \mathrm{MHz}) \text { in landing } \\
\text { areas } \\
\text { 2. Obtain the subsurface } \\
\text { structure and possible } \\
\text { water-ice of landing areas }\end{array}$ & $\begin{array}{l}\text { 1. Subsurface structure of landing } \\
\text { areas } \\
\text { 2. Possible water-ice of landing } \\
\text { areas }\end{array}$ & $\begin{array}{l}\text { To investigate the regolith } \\
\text { characteristics and } \\
\text { water-ice distribution on } \\
\text { the Martian surface, and } \\
\text { to obtain the conditions } \\
\text { and environmental } \\
\text { information of life }\end{array}$ \\
\hline \multirow[t]{2}{*}{ MOSIR } & $\begin{array}{l}\text { 1. Acquire echo data of } \\
\text { dual-frequency } \\
\text { dual-polarization radar of } \\
\text { Martian surface and subsurface } \\
(10-20 \mathrm{MHz}, 30-50 \mathrm{MHz}) \\
\text { 2. Obtain the subsurface } \\
\text { structure and possible } \\
\text { water-ice of exploration areas }\end{array}$ & $\begin{array}{l}\text { 1. Subsurface water-ice distribution } \\
\text { at Mars medium and high latitudes } \\
\text { 2. Water-ice exploration in the } \\
\text { Mars polar regions } \\
\text { 1. Regolith type and distribution } \\
\text { 2. Regolith subsurface structure }\end{array}$ & \\
\hline & $\begin{array}{l}\text { 1. Spectral data of ultra-low } \\
\text { frequency detection in the } \\
\text { Earth-Mars transfer orbit } \\
\text { section }(10 \mathrm{KHz}-10 \mathrm{MHz}) \\
\text { 2. Detection data of } \\
\text { ionosphere (TEC) in the } \\
\text { Mars-orbiting section } \\
(10-20 \mathrm{MHz}, 30-50 \mathrm{MHz})\end{array}$ & $\begin{array}{l}\text { 1. Mars atmosphere escape } \\
\text { processes } \\
\text { 2. Interplanetary very low } \\
\text { frequency radio } \\
3 \text {. The conductivity and vertical } \\
\text { structure and variability of the } \\
\text { ionosphere }\end{array}$ & $\begin{array}{l}\text { To measure the } \\
\text { characteristics of Mars } \\
\text { ionosphere, plasma } \\
\text { environment and escape } \\
\text { processes, surface } \\
\text { atmospheric properties } \\
\text { and meteorology; }\end{array}$ \\
\hline MINPA & $\begin{array}{l}\text { 1. The data of Mars ions and } \\
\text { neutral particles } \\
\text { 2. Physical parameters of Mars } \\
\text { space environment such as } \\
\text { density, velocity and } \\
\text { temperature of main ion } \\
\text { components } \\
\text { 3. Distinguish the main neutral } \\
\text { particle components such as } \mathrm{H} \text {, } \\
\text { He and O }\end{array}$ & plasma environment & $\begin{array}{l}\text { To study the Mars } \\
\text { magnetic field and interior } \\
\text { structure and obtain the } \\
\text { law of interaction between } \\
\text { solar activity and Mars }\end{array}$ \\
\hline MEPA & $\begin{array}{l}\text { The data of interaction } \\
\text { between solar wind, } \\
\text { high-energy particles and Mars }\end{array}$ & $\begin{array}{l}\text { 3D spatial distribution of radiation } \\
\text { energy spectrum and components } \\
\text { of high-energy particles }\end{array}$ & \\
\hline
\end{tabular}


Table 8 (Continued)

\begin{tabular}{|c|c|c|c|}
\hline Payloads & Expected scientific data & Expected scientific achievements & Scientific objectives \\
\hline MOMAG & $\begin{array}{l}\text { magnetic field data within } \\
\text { 3.5 Rm above the Martian } \\
\text { surface, and to make a spatial } \\
\text { distribution map of Mars } \\
\text { magnetic field }\end{array}$ & \multirow{2}{*}{$\begin{array}{l}\text { Based on the positions of the } \\
\text { orbiter and the rover as well as the } \\
\text { measured magnetic field, Mars } \\
\text { ionosphere height, current strength, } \\
\text { distribution and other } \\
\text { characteristics are to be retrieved }\end{array}$} & \\
\hline RoMAG & Mars surface magnetic field & & \\
\hline MCS & $\begin{array}{l}\text { Basic characteristics and time } \\
\text { variation of atmospheric } \\
\text { temperature, pressure and } \\
\text { wind field. Meteorological } \\
\text { parameters and acoustic data } \\
\text { at particular times (such as } \\
\text { dust storms) }\end{array}$ & $\begin{array}{l}\text { Martian surface wind field and air } \\
\text { pressure measurement }\end{array}$ & \\
\hline / & Mars orbit data & Mars gravity field & \\
\hline MMS & $\begin{array}{l}\text { 1. } 72 \text { bands spectral images } \\
\text { with spatial resolution of } \\
1.06 \mathrm{~km}-3.2 \mathrm{~km} / \text { pixel and } \\
\text { spectral range of } \\
450 \mathrm{~nm}-3400 \mathrm{~nm} \\
2.72 \text { bands and full bands } \\
\text { spectral images covering the } \\
\text { interested regions with spatial } \\
\text { resolution of } \\
265 \mathrm{~m}-3.2 \mathrm{~km} / \text { pixel and } \\
\text { spectral range of } \\
450 \text { nm-3400 nm } \\
3 . \text { Mineral type and } \\
\text { distribution of the whole Mars } \\
\text { and regions of interest }\end{array}$ & $\begin{array}{l}\text { 1. Large-scale survey of major } \\
\text { minerals } \\
\text { 2. Major type and distribution of } \\
\text { Mars rocks types } \\
\text { 3. Mineral resources and } \\
\text { enrichment areas on the Martian } \\
\text { surface }\end{array}$ & $\begin{array}{l}\text { To analyze the Martian } \\
\text { surface materials } \\
\text { composition and to obtain } \\
\text { the basic information on } \\
\text { the chemical evolution }\end{array}$ \\
\hline MSCam & $\begin{array}{l}\text { 1. Multi-spectral data of } 8 \\
\text { bands visible near-infrared } \\
\text { spectra of the landing area } \\
\text { 2. True color and false color } \\
\text { images of the landing area } \\
\text { from } 1.5 \mathrm{~m} \text { to infinity }\end{array}$ & $\begin{array}{l}\text { 1. Martian surface rock lithology } \\
\text { 2. Martian surface minerals } \\
\text { 3. Martian surface secondary } \\
\text { minerals }\end{array}$ & \\
\hline MarSCoDe & $\begin{array}{l}\text { 1. High-resolution LIBS } \\
\text { spectral data of study targets } \\
\text { of the landing area from } \\
240 \mathrm{~nm} \text { to } 850 \mathrm{~nm} \\
\text { 2. Elemental composition } \\
\text { identification and their } \\
\text { content, major minerals of the } \\
\text { landing area }\end{array}$ & & \\
\hline
\end{tabular}

\section{Summary}

With the development of science and technology, especially the space technology, solar system has been explored by many countries using a variety of methods, including the Moon, terrestrial planets and their satellites, asteroids, comets and etc. The geological background and space environment of celestial bodies in the solar system are deeply investigated to study the formation and evolution history of solar system which are the most fundamental scientific problems of planetary research. 
China's first Mars exploration mission focuses on the investigation of Mars magnetosphere, ionosphere and atmosphere as well as the changes and evolution of Mars climate by measuring the structure, composition and characteristics of Mars magnetosphere, ionosphere and atmosphere. It will investigate the distribution, composition and characteristics of Mars surface, especially the distribution of aqueous minerals, and study the environmental evolution of Mars. Besides, the topography and geomorphology of the Mars will be mapped to study the role of wind, water-ice, volcano, impact and tectonic activities in the formation and transformation of Mars surface topography, which also helps to reveal the geological features and evolution history of the Mars. Comparative planetary studies will be carried out, the global image will be acquired, and the preferred sampling and landing areas will also be selected. The mission will analyze the content and distribution of major elements on Martian surface, the distribution of various minerals and rocks, especially sedimentary rocks on Martian surface, and study the geological evolution history of the Mars. It will explore the distribution and storage of ground water and study the water escape and transfer process. Mars magnetic field and gravity field will be characterized and compared with other terrestrial planets. On the basis of these investigations, the mission will the study of the living environment and the evolution history of Mars as well as the origin and evolution of the solar system, which can provide clues and support for the most basic scientific problems faced by planetary exploration.

Tianwen-1 is going to orbit, land and release a rover all on the very first try, and coordinate observations with an orbiter. If successful, it would signify a major technical breakthrough. Scientifically, Tianwen-1 is a comprehensive mission to investigate the Martian morphology, geology, mineralogy, space environment, and water-ice distribution. There are some complementarity and uniqueness of Tianmen-1 with other missions, for example MOMAG and RoMAG can measure Mars space and surface magnetic field, MOSIR and RoPeR can investigate water-ice by means of the dual-polarization and full-polarization radar, respectively. Similar instruments such as MarSCoDe can measure different representative results of Mars on the different landing site. HiRIC can provide high resolution images and DEM where other missions have not been imaged.

China's first exploration of Mars will be another important landmark project after lunar exploration, which will advance our understanding of the origin, evolution and characteristics of the Earth, solar system and the universe and promote the development of space science and planetary science.

Open Access This article is licensed under a Creative Commons Attribution 4.0 International License, which permits use, sharing, adaptation, distribution and reproduction in any medium or format, as long as you give appropriate credit to the original author(s) and the source, provide a link to the Creative Commons licence, and indicate if changes were made. The images or other third party material in this article are included in the article's Creative Commons licence, unless indicated otherwise in a credit line to the material. If material is not included in the article's Creative Commons licence and your intended use is not permitted by statutory regulation or exceeds the permitted use, you will need to obtain permission directly from the copyright holder. To view a copy of this licence, visit http://creativecommons.org/licenses/by/4.0/.

\section{References}

W.B. Banerdt, S.E. Smrekar, D. Banfield et al., Initial results from the InSight mission on Mars. Nat. Geosci. 13, 183-189 (2020)

N. Barlow, Mars: An Introduction to Its Interior, Surface and Atmosphere (Cambridge University Press, New York, 2014)

J.P. Bibring, Y. Langevin, A. Gendrin et al., Martian surface diversity as revealed by the OMEGA/Mars Express observations. Science 307(5715), 1576-1581 (2005) 
J.P. Bibring, Y. Langevin, J.F. Mustard et al., Global mineralogical and aqueous Mars history derived from OMEGA/Mars Express data. Science 312, 400-404 (2006)

M.H. Carr, The Surface of Mars (Yale University Press, New Haven, 1981)

J.A. Crisp, M. Adler, J.R. Matijevic et al., Mars Exploration Rover mission. J. Geophys. Res., Planets 108(E12), 8061 (2003)

ESA, ExoMars-Science Management Plan, http://exploration.esa.int/science-e/www/object/doc.cfm? fobjectid=46850, accessed 2014

C. Freissinet, D.P. Glavin, P.R. Mahaffy et al., Organic molecules in the Sheepbed Mudstone, Gale Crater, Mars. J. Geophys. Res., Planets 120(3), 495-514 (2015)

A. Gendrin, N. Mangold, J.P. Bibring et al., Sulfate in Martian layered terrains: the OMEGA/Mars Express view. Science 307(5717), 1587-1591 (2005)

J. Gómez-Elvira, C. Armiens, L. Castañer et al., REMS: the environmental sensor suite for the Mars Science Laboratory Rover. Space Sci. Rev. 170(1-4), 583-640 (2012)

J.E. Graf, R.W. Zurek, H.J. Eisen et al., The Mars Reconnaissance Orbiter mission. Acta Astronaut. 57(2-8), 566-578 (2005)

J.P. Grotzinger, Habitability, taphonomy, and the search for organic carbon on Mars. Science 343(6169), 386-387 (2014)

D.M. Hassler, C. Zeitlin, R.F. Wimmer-Schweingruber et al., Mars' surface radiation environment measured with the Mars Science Laboratory's Curiosity rover. Science 343(6169), 1244797 (2014)

J.W. Head III, C. Pieters, Geological evolution of the terrestrial planets: 60 years of exploration and discovery, in Sputnik: 60 Years Along the Path of Discoveries (2018), pp. 199-223

J.W. Head III, H. Hiesinger, M.A. Ivanov et al., Possible ancient oceans on Mars: evidence from Mars Orbiter Laser Altimeter data. Science 286(5447), 2134-2137 (1999)

B.M. Jakosky, R.P. Lin, J.M. Grebowsky et al., The Mars Atmosphere and Volatile Evolution (MAVEN) mission. Space Sci. Rev. 195(1-4), 3-48 (2015)

C.L. Johnson, A. Mittelholz, B. Langlais et al., Crustal and time-varying magnetic fields at the InSight landing site on Mars. Nat. Geosci. (2020). https://doi.org/10.1038/s41561-020-0537-x

A.S.K. Kumar, P. Chauhan, Scientific exploration of Mars by first Indian interplanetary space probe: Mars Orbiter Mission. Curr. Sci. 107(7), 1096-1097 (2014)

P.R. Mahaffy, C.R. Webster, S.K. Atreya et al., Abundance and isotopic composition of gases in the Martian atmosphere from the Curiosity rover. Science 341(6143), 263-266 (2013)

NASA, Mars Curiosity Rover, https://mars.nasa.gov/msl/mission/science/objectives/, accessed 2011

NASA, InSight Mission Overview, https://mars.nasa.gov/insight/mission/overview/, accessed 2018

NASA, Mars 2020 Mission Overview, https://mars.nasa.gov/mars2020/mission/overview/, accessed 2020

R. Orosei, S.E. Lauro, E. Pettinelli et al., Radar evidence of subglacial liquid water on Mars. Science 361(6401), 490-493 (2018)

Z.Y. Ouyang, Q. Liu, Another Earth: Road to Mars (Beijing Institute of Technology Press, Beijing, 2009)

Z.Y. Ouyang, F.G. Xiao, Major scientific issues involved in Mars exploration. Spacecr. Environ. Eng. 28(3), 205-217 (2011)

M. Pätzold, B. Häusler, G.L. Tyler et al., Mars Express 10 years at Mars: observations by the Mars Express Radio Science Experiment (MaRS). Planet. Space Sci. 127, 44-90 (2016)

F. Salese, M. Pondrelli, A. Neeseman et al., Geological evidence of planet-wide groundwater system on Mars. J. Geophys. Res., Planets (2019). https://doi.org/10.1029/2018JE005802

R.S. Saunders, R.E. Arvidson, G.D. Badhwar et al., 2001 Mars Odyssey mission summary. Space Sci. Rev. 110(1-2), 1-36 (2004)

O. Sharaf, S. Amiri, S. AlDhafri et al., Sending hope to Mars. Nat. Astron. 4, 722 (2020). https://doi.org/10. 1038/s41550-020-1151-y

D.E. Smith, M.T. Zuber, S.C. Solomon et al., The global topography of Mars and implications for surface evolution. Science 284, 1495-1503 (1999)

P.H. Smith, L. Tamppari, R.E. Arvidson et al., Introduction to special section on the Phoenix Mission: landing site characterization experiments, mission overviews, and expected science. J. Geophys. Res. 113, E00A18 (2008)

D.J. Stevenson, Mars' core and magnetism. Nature 412(6843), 214-219 (2001)

W.X. Wan, C. Wang, C.L. Li et al., China’s first mission to Mars. Nat. Astron. 4, 721 (2020)

C.R. Webster, P.R. Mahaffy, S.K. Atreya et al., Mars methane detection and variability at Gale crater. Science 347(6220), 415-417 (2015)

C.R. Webster, P.R. Mahaffy, A.K. Atreya et al., Background levels of methane in Mars' atmosphere show strong seasonal variations. Science 360(6393), 1093-1096 (2018)

A. Wilson, A. Chicarro, Mars Express: the scientific payload. ESA Publications Division (2004)

P.J. Ye, Z.Z. Sun, W. Rao et al., Mission overview and key technologies of the first Mars probe of China. Sci. China, Technol. Sci. 60(5), 649-657 (2017)

C. Zeitlin, D.M. Hassler, F.A. Cucinotta et al., Measurements of energetic particle radiation in transit to Mars on the Mars Science Laboratory. Science 340(6136), 1080-1084 (2013) 
Publisher's Note Springer Nature remains neutral with regard to jurisdictional claims in published maps and institutional affiliations.

\title{
Authors and Affiliations
}

Chunlai $\mathrm{Li}^{1,2} \cdot$ Rongqiao Zhang ${ }^{3}$. Dengyun $\mathrm{Yu}^{4} \cdot$ Guangliang Dong ${ }^{5}$. Jianjun Liu ${ }^{1,2}$. Yan Geng ${ }^{3}$. Zezhou Sun ${ }^{6}$. Wei Yan ${ }^{1} \cdot$ Xin Ren $^{1} \cdot$ Yan Su ${ }^{1,2}$ - Wei Zuo ${ }^{1,2}$. Tielong Zhang ${ }^{7,8}$. Jinbin $\mathrm{CaO}^{9}$. Guangyou Fang ${ }^{10}$. Jianfeng Yang ${ }^{11} \cdot$ Rong Shu $^{12}$. Yangting Lin $^{13}$. Yongliao Zou ${ }^{14}$. Dawei Liu ${ }^{1}$ • Bin Liu ${ }^{1}$ • Deqing Kong ${ }^{1}$. Xinying Zhu ${ }^{1}$. Ziyuan Ouyang ${ }^{1,15}$

\author{
C. Li \\ licl@nao.cas.cn
}

$凶$ J. Liu

liujj@nao.cas.cn

1 Key Laboratory of Lunar and Deep Space Exploration, National Astronomical Observatories, Chinese Academy of Sciences, Beijing 100101, China

2 University of Chinese Academy of Sciences, Beijing 100049, China

3 Lunar Exploration and Space Engineering Center, Beijing 100190, China

4 China Aerospace Science and Technology Corporation, Beijing 100048, China

5 Beijing Institute of Tracking and Telecommunications Technology, Beijing 100094, China

6 Beijing Institute of Spacecraft System Engineering, Beijing 100094, China

7 University of Science and Technology of China, Hefei 230026, China

8 Space Research Institute, Austrian Academy of Sciences, Graz, Austria

9 Beihang University, Beijing 100191, China

10 Aerospace Information Research Institute, Chinese Academy of Sciences, Beijing 100190, China

11 Xi' an Institute of Optics and Precision Mechanics, Chinese Academy of Sciences, Xi' an 710119, China

12 Shanghai Institute of Technical Physics, Chinese Academy of Sciences, Shanghai 200083, China

13 Institute of Geology and Geophysics, Chinese Academy of Sciences, Beijing 100029, China

14 State Key Laboratory of Space Weather, National Space Science Center, Chinese Academy of Sciences, Beijing 100190, China

15 Institute of Geochemistry, Chinese Academy of Sciences, Guiyang 550081, China 